\title{
Indenting the Proverbs: Some Notes on Translation
}

\author{
Vijay Sheshadri
}

\begin{abstract}
Translation is a symbiotic act that transacts between one language and another and hence cultures. Translation enables a culture to be introduced into a new geographical and psychic space avoiding effacement of a culture, reflecting the hegemonic relationship between the two cultures. Today, absence of translation can be an anathema to the flourishing of a literature that has roots invariably in a region, a specific native context. Thus translation can provide a platform of multiple voices for literature to flourish.

The paper is divided into two sections. The First section will deliberate on Translation in general and then go on to view translation as an attempt at interpreting two cultures. In the Second section, by selecting a few popular Proverbs from the Myasabedas, a tribal community living in and around Challakere, Jagaloor and Molakalmooru taluks of Chitradurga District in Central Karnataka, an attempt will be made to show how a pluralistic community of multiple voices can strengthen the fabric of a country's literature without resorting to narrow ethnicity. The translated proverbs from the Kannada original into English will be subjected to a close study to examine the dual nature of Translation, in the making or marring the contexts of a specific text and its space in Indian literature.

"In Principle a work of art has always been reproducible. Man made artifacts could always be imitated by men. Replicas were made by pupils in practice of their craft, by masters for diffusing their works, and finally, by third parties in pursuit of gain"
\end{abstract}


Translation of the oral into the written, I presume, is an attempt at enunciating the verbal into the linguistic, the transformation of sensory perception into the written. In other words, it is an act of making the world "hear" operating with the motif or belief that it would be an all-embracing activity.

In principle, all languages are commensurable as opposed to American pragmatism observes Ajaz Ahamed. (Ahamed, 2004) In any act of translation, I feel that capturing sense is an easier task than that of making someone spot, see or experience sensibilities. For instance, translating Bhagavadgita into the tongue of an indigenous culture is as difficult as translating a native culture and language into another. Since language is embedded in power politics under the sign of globalization, the acquisition of English as a language invariably reflects the class, say bourgeois or elite class. Hence, in today's world of information technology where various information bombard our psyche, in a country like India where there is population explosion, language operates as a pointer of an episteme, a sort of diagnostic system. Therefore, any translation of an oral culture of Kannada into English results in English getting richer. Since English has become one of the languages of India and much sought after today, it is wielding much power vis-à-vis day to day affairs as well as in the academic circles. Another factor is, India is advocating free trade policy and opening its market to foreign investors has added more power and glamour to English in India. In other words if a person is a glib in English, he is intelligent. Immaculate use of English results in bestowing undue credit and intelligence to the person speaking in English. Hence, Indian Writing in English and other regional languages and literature (not Desi for god's sake) should be studied as comparative literature and not as a hegemonic structure. It also should not be viewed from that sweeping generalization of Fredric Jameson who calls all third world literatures are national allegories. I think it is here that translations vital contribution rests.

In a polylingual and polycultural situation like India, 
translation should aim at building a chronopolitan culture (Werner, 2000: 331-345) 1 that aims at homogeneity and not difference. In doing so, translational process paves way for the interfacing of Translator-Reader-Source Text, resulting in what Deborah Bower opines: "The wholeness of one person can be received in a known context by the wholeness of another". (Bower, 1988: 66) There rests a tendency to anglicize and clothe the oral/regional (Kannada experience here) thus falling into the trap of "English as universal" or "Postcoloniality as the inevitable real condition, a paradigmatic exercise of enlightenment". In the words of Theo Hermans,

Translation, then, is the visible sign of the openness of the literary system, of a specific literary system; it opens the way to what can be called both subversion and transformation depending on where the guardians of the dominant poetics, the dominant ideology stand! (Hermans, 1985: 237)

Any translator of a folk/oral narrative confronts three referential systems-the verbal/oral into text, the system of language and culture into which the verbal/oral gets translated into (Kannada here) and the cultural system into which it gets re-created as a meta text through English. Culture no doubt is a site of contestation and translation must negotiate the complex realities of language which the culture comprises. Translation thus is a process of unlearning, de-colonizing the mind. When one translates oral into the written, English in this case, one is just not asserting his ego but also showing the richness embedded in a tradition which the west has been ignorant of. The translational process of oral to the written can be viewed as a percolation function where the text gets re-created with a new set of ideological framework generating a specific response. This sort of an enterprise I suppose, results in breaking down of hierarchies, a discursive project of writing back or writing home or returning the gaze. Just as we have received translated texts from the west since Sophoclean times, the non-western has been little talked of. Hence this endeavour. Susan Bassnett McGuire's observations are apt here: 
Language, then is the heart within the body of culture, and it is the interaction between the two that results in the continuation of life-energy. In the same way that the surgeon, operating the heart, cannot neglect the body that surrounds it, so the translator treats the text in isolation from the culture at his peril". (McGuire, 1980: 14)

It is here that writing and translation render their vital contribution. Just imagine these voices not recorded in Kannada language? A whole community would have hit by an epidemic called aphasia and would have been erased from this world. But the other vital question that needs more attention is, are the translations of Folk Narratives meant for readers who are ignorant of the original or for a particular set of readers? The answer would be yes because the attempt is to say the same thing by re-creation in a different medium. In other words it is not just a function of transmitting information but an endeavour of transmitting essential things in a meticulous fashion. This then pushes the translator to muse over the translatability of the original work since the oral creation is devoid of any mass appeal but sets out as a matter of tradition or ritual.

The oral tradition-stories, epics and songs of the peoplewhich formerly were filed as set pieces are now beginning to change. The storytellers who used to relate inert episodes now bring them alive and introduce into them modifications which are increasingly fundamental. There is a tendency to bring conflicts up to date and to modernize the kinds of struggle which the stories evoke, together with the names of heroes and the types of weapons. The method of allusion is more and more widely used. The formula 'this all happened long ago' is substituted by that of 'what (were/are) going to speak of happened somewhere else, but it might well have happened here today, and it might happen tomorrow" (Fanon, 1967, 85:193) 
In the present day scenario where every nation is adjudicated as an Imagined Community, it becomes essential for anyone to be aware of the fact that the trait of any nation is not homogenous. India no doubt serves as an interesting exemplar. In a polycultural situation like India where there is ample room for languages to grow and hence cultures to flourish, there is definitely an opportunity for a fascinating study of cultures. India as we all know is responding to the changes that have been going on in the entire world over due to the onset of globalization. Under the sign of Information Technology, the shrinking of spaces, geographical as well as psychological, is taking place leading to the notion of the whole world as the "Global Village". We are not far from the days where the last of the first nations' people will be effaced from this universe, leaving us to comprehend the fact that the basics of mankind are lost forever.

My attempt in this paper is to showcase (not the kind of showcasing that occurs during any cultural fest or with the visit of foreign dignitaries) the Mysabedas a tribal community living in Chitradurga district in central part of Karnataka state. These are communities who were untouched by the technological changes that were going on as recent as twenty years ago. Today they are on the verge of erasure vis-à-vis their traditional mores and customs. My attempt in this paper reflects what Claude Levis Strauss observes:

Any man can turn himself into an ethnographer and go and share on the spot the life of a society in which his is interested; on the other hand, even if he becomes a historian or an archaeologist, he will never enter directly into contact with a vanished civilization, but will only do so through the written documents or figurative monuments which this society-or othershave left. (Levis-Strauss, 1976: 326)

Among the Myasabedas and Kadugollas, there is a sub sect called Oorubedas, village hunters and Ooru Gollas, village shepherds. If the Kadugollas speak good Kannada, the Oorugollas 
speakTelugu. Myasabedas who trace their native origins to Andhra Pradesh, the neighbouring state, speak Telugu in their settlements and while interacting with the outside world they speak Kannada. Interestingly, the literatures of Kadugollas and Myasabedas are in Kannada language. The proverbs and riddles that are in circulation among the communities are not clan or group specific. But as a rare exception or instance, some proverbs are only about Myasabedas. The following proverbs are in circulation among the Myasabedas:

1. Will the stealer of an ox forget the rope?

$$
\text { ఎ ఫ్తిన ప్ ळగ్గ డురితాని }
$$

2. Hunter is a thief and untouchable is a liar.

$$
\text { బిఁడ ప్ళ్ళ }
$$

3. Even when in need of Jaggery, do not believe a Beda, the huntsman.

$$
\text { బిల్లడ ळంగిద్దరు బిలడనన్ను నంబబారడు }
$$

4. If one grows the Jaali thorn, its danger to the legs, danger to life if one shelters a huntsman.

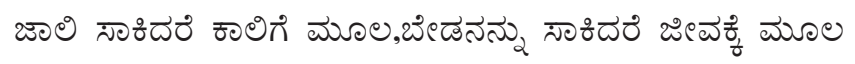

5. If unmoved, buttocks will catch termites.

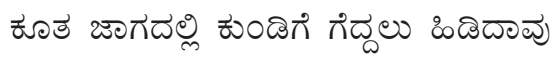

6. A voyeuristic huntsman rubs his organ to the fence.

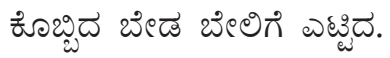

7. No graze for the cattle, no medicine for the Myasabeda

$$
\text { రాలిఁగి డిలవిల్ల బిఁడనిగి డుద్దిల్ల }
$$

\section{Translation Today}


8. He ate where food was aplenty, slept in a warm place

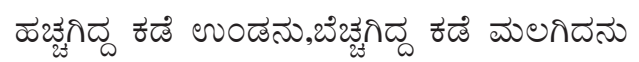

9. Man with skinny buttocks, what does he know about the rains?

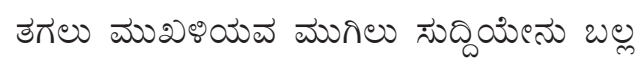

10. Still cloud the winds disturbed/winds scattered the gathered cloud

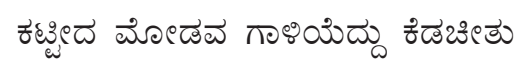

11. Disciplined workers are achievers

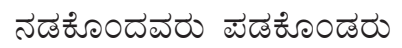

12. To the clan, clan is a destroyer, to the fields, a limping ox

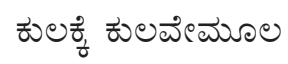

13. There is no limit to wants/desires, beggars are shameless.

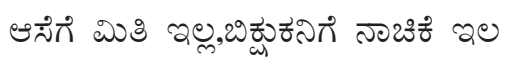

14. A Seer less monastery and headless house are one

$$
\text { గురులిల్లద డుఠ ఃంయరల్లడ డునియాంందిల }
$$

15. After the guru its gulla, his disciple

$$
\text { గురులినంతర గుడ్ణ }
$$

16. To the foolish king, a moronic prime minister

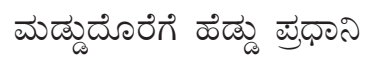

17. Destitute widow licked the rolling pin. 


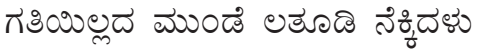

18. A stopper to ears, and a thorn to the eyes.

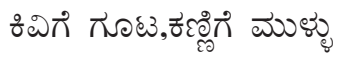

19. No relatives for the wayward and no gods for the dead one.

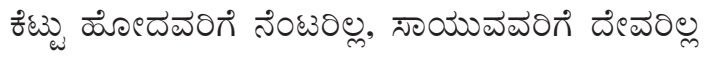

20. More you pay, value for your money.

$$
\text { అంతది ซృసు, అంతదిల పడలి }
$$

21. It's like desiring a hombale, the plantain inflorescence in a kaare weed bush.

$$
\text { ซరి กడాడల్లి ఓంబాళ బయిసిదంతే }
$$

22. Arriving at an empty house, departed knocking the door.

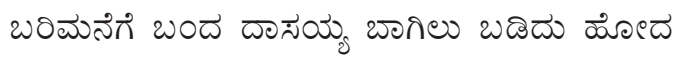

23. What if you bite the Roti from any side?

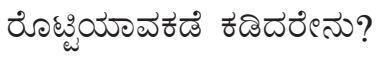

24. Man without a tool left early in the morning (to work)

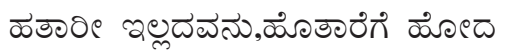

25. An incessant talker/cribber is the biggest of all irritations.

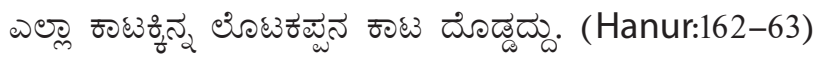

In the above proverbs, the first seven to eight are exclusively about Myasabedas and they use it quite frequently among themselves during every day talk. The first proverb "will the stealer of an ox forget the rope" is very popular among both 
Myasabedas and Kadugollas who view the ox as holy, as property and riches. As a matter of fact, when a group of thieves drive away a herd of cattle, the method involved is different than a thief walking away with an ox or calf. If a thief walks away with an Ox forgetting the rope, it is of no use for him since he cannot control the $O x$ as he wishes and it might run away from him. But when a herd of cattle is driven together and stolen, ropes do not have any role to play. In this fashion, this proverb has surfaced vis-à-vis an instance where a thief attempts to walk away with an ox or a calf.

"Myasabeda is a thief and Untouchable a liar" is a proverb that has moorings in caste related issues. In a class, caste-oriented society like India, proverbs that praise or mock a particular caste, their lifestyles, professions, traits are in abundance. Along with their caste or profession of cattle rearing, the Myasabedas also took up the job of being soldiers and hunting. If the job of waging war or hunting was not possible either due to old age or for any other reason, a Myasabeda had to lead his life at least by rearing cattle. As he desires to do this, chances of he getting the cattle might be very slim, since he is well trained either to hunt or to wage war. Chances of he eyeing a cattle belonging to someone or may be more the practice of stealing either a sheep or an ox from a shed amongst themselves in the settlement is still in vogue according to some Myasabedas. At the same time, one can infer that their chances of becoming big thieves are also very thin. Keeping this in mind, the word "Myasabeda thief" has been attached to the word Untouchable thief" as a practice and rhyming word. As a sequel to these, proverbs dealing with caste mocking are seen in "Though in need of Jaggery do not believe the Myasabeda" "If you grow a Jaali, danger to your legs" and "if you raise a Myasabeda danger to your life" have been in circulation or practice.

Bedanayakas who have experience in hunting, fighting, dwelling in the forests have remained to this day as adventurous youths full of life and energy. Such young Bedanayakas bustling with youthful energy neglect any thorny fence and do not clear it either with hands or legs. When his sexual desire is intense, 
placing his penis or organ on the thorny fence the Bedanayaka youth scratches it. Such will be the intensity of his sexual desire in his youth opines an elderly Bedanayaka tribal explaining the meaning and intension of the proverb "A Voyeuristic huntsman rubs his organ to the fence". The proverb "if unmoved buttocks will catch termites" is related to the legal disputes of not only Bedanayakas and Kadugollas but also to other tribal communities. To the Myasabedas their clan, clan goddesses, the patterns of division in the clan, marriage customs are of vital importance. Any dispute or arguments relating to the above mentioned issues would take a minimum of three days to settle or else can prolong to the extent of a week. If the dispute is about gods or its priest, it might go unsolved and reach Kattamane, the house of justice and later Gurumane, the supreme house of justice. In the present day context these disputes are reaching the courts or law houses in the cities. In the past, these disputes would not go beyond the Kattemane, the supreme house of justice and the dispute would not settle for ages. Keeping the legal disputes of such nature the above proverb was used.

The proverbs "He ate where food was aplenty and slept in a warm place" and "No graze for the cattle, no medicine for the Myasabeda" delineate the lifestyles and patterns in times of prosperity and in times of drought. The first proverb is quite popular among majority of the tribal communities. If it rains and forests are full of greenery, there will be grass in abundance for the cattle to feed on. If the cattle have grazed well, life for its overseer would be smooth and trouble free because the milk and curd of cattle provide enough food for forests dwellers. But if the whole place dries up, the cattle fall short of grazing fields and the Kilaris have to drive the cattle in search of greener areas where there is sufficient grass for the cattle. This driving from one place to another is a tiresome job and results in shortage of food for both the cattle and its overseers the Kilaris. All these proverbs are used keeping the rain, the greenery of the forest, grass for the cattle and the lifestyles of the Myasabedas as a backdrop. 
Be it the forest dwellers or the village dwellers, their future days or lifestyles depend heavily on rain. But nature has its own cycle. One year it might rain profusely and in another it might not. Hence the proverb"Man with skinny buttocks, what does he know about the rains" to imply that it is nearly impossible to decipher the happenings in nature for the human mind. An extension of this proverb "Winds scattered the gathered still clouds" seems to imply more symbolic meaning than literal meaning. This proverb perhaps can be applied to any work that is about to bear fruition or results being destroyed, or any work getting destroyed at the point of yielding fruits.

The proverb "Disciplined workers are achievers" is very much in circulation in and round Nayakanahatti settlement. The genesis of this proverb can be traced to a miracle performed by Sharana Thippeswamy. When chieftain Baodimallappanayaka was constructing a pond named Hirekere at Chikkere in Nayakanahatti settlement, his coffers got empty. At that juncture, Sharana Thippeswamy would visit the pond every evening and ask all the workers to erect a small mound in front of each one. Later with his staff when Sharana Thippeswamy touched these mounds, the mud turned into money only if the worker has toiled that day. If he had not, the mud would remain as mud. In this fashion, people who toiled got rewarded from Thisppeswamy and the proverb is used in this connection. Incidentally this proverb seems to be of great importance to the tribals of Nayakanahatti, Challakere, Jagaloor and Molakalmooru. It appears this proverb is not in circulation among other regions or settlements.

Proverbs like "To the Clan, Clan is the destroyer, limping ox to the fields" and "there is no limit to desires/wants, beggars are shameless" are not just limited to Chitradurga district or Myasabeda tribal settlements but is in circulation in almost all parts of Karnataka. This proverb reminds of the bickering that arouse as brothers grew up due to variegated reasons, an age-old issue. To this proverb, "limping Ox to the fields" is a later inclusion. It is true that ox is essential to plough the fields but it is difficult to 
plough a field and reap harvest using a lame ox. Just as healthy ox without a handicap is essential to till a field, for betterment of life, compatibility between clans is the most essential factor. If there is a breakdown of relationships between clans and if the ox is lame, tilling cannot be fast and harvest cannot be reaped on time resulting in impediment to progress. In fact this proverb that is in circulation in all parts of Karnataka has somehow slipped into the Myasabeda community. Under normal circumstances, this proverb doesn't acquire meaning and significance in the Myasabeda community because in tribal settlements, the bondage between clans is more solid and strong and very seldom there is breakdown of relationships. The bond is so strong so much so that it becomes very difficult for an outsider to spot and name the person belonging to a particular hut because you see him hopping from one hut to another with absolute ease. Moreover, each one would be addressing the other either as brother, sister, uncle, aunty, big/elder father, elder mother though these relationships might not be associated with the mode of their address. In tribal life, socializing is very important and first preference is given to the concept of unity in the tribe. Hence the statement "To the clan, clan is the destroyer" which is of civilized texture doesn't seem to be compatible with either Bedanayaka or Kadugolla tribal lifestyles.

Similarly the proverb"No relatives for the wayward, no God for the dead" doesn't seem to fit into the schema of life patterns or styles of the Myasabeda community. It is a known fact that it is quite impossible to have a very rich man and a very poor man at a time. Since the tribal preoccupation or jobs are almost one, the income level would be uniform. To top it all, the statement "To the dead there is no God" doesn't agree with the tribal outlook towards life because birth or death in any hut of the settlement becomes an important event for everyone. Folks congregate and unite invariably during a death in the settlement if not during other occasions because they believe that the dead person would go and join their progenitors in heaven. Since the dead person would be the eldest and godlike after his death, the ritual of the 
dead man becomes important and holy to all the tribes of the settlement. Though the proverb "No relatives for the wayward, no Gods for the dying" is in circulation among the Myasabeda tribes, it doesn't seem to gel with the outlook towards life.

Other proverbs like "There is no limit to want, beggars are shameless" "A Monastery without a guru, house without a head are one" "After the guru, its gudda his disciple" "To the foolish king, a moronic prime minister" "Destitute widow licked the rolling pin" "More you pay, value for your Money" have all come from towns, villages and cities and have percolated into the Bedanayaka communities.

There goes a saying in Kannada that, "The Vedas might go wrong but not the Proverbs". How true the statement turns out to be when one examines the Proverbs of the Myasabedas! The Proverbs not only provide us the cultural milieu but also the world of the lived experiences of a community that was totally cut off from the civilized world.

To conclude, folk literatures are to be translated because of their originality in thought and of cultural significance. Translation, no doubt might be considered less significant than the original but the original has affinity with the translation, a vital affinity. The task of the translator in translating an oral piece into the written should focus on the intention of the original getting reflected in the language into which he is translating. Basing on the premise that the translated work is not a literary work but a literary enterprise marked by an attempt to integrate language, literature, culture etc., because "the intention of the author is spontaneous, primary, graphic; that of the translator is derivative, ultimate, ideational. Translation is midway between poetry and doctrine". (Benjamin: 77-78) The translation of an oral piece into the written no doubt suffers from a loss, the loss of the rhythm of the original language. But making the target language adhere close to the sense of the original language perhaps could compensate this loss because, 
"Translation proposes a sort of parallel universe (to that of the original work) another space and time in which the text reveals other, extraordinary possible meanings. For these meanings, however, there are no other words, since they exist in the intuitive no man's land between the language of the original and the language of the translator" (Manguel, 1977: 276)

\section{NOTES}

1. Chronopolitanism is developed as a theoretical as well as ethical opening that reconfigures the search for a world political community in time and history. It is a move that has the explicit aim of extending social and political responsibilities to past, present and future generations, as well as to the diversity of histories and rhythms of life that co-exists in the global present. S. Werner, "The Chronopolitan Ideal:Time, Belonging and Globalisation". Time and Society, Vol 9, Nos 2\&3. 2000 Print.

\section{REFERENCES}

Ahamed, Ajaz. Key Note Address. 2004. National Seminar on Translation and Socio-literary Space, 12-14th February Department of English and Modern European Languages, Jamia Milia Islamia University, New Delhi.

Benjamin, Walter. 1999."The Work of Art in the age of Mechanical Reproduction" in Illuminations. Pimlico: London, Print. pp. 212

Bower, Deborah. 1988. "Squaring the Circle: The Problem of Translation in The Temptations of Big Bear" in W. H. New Ed. Canadian Literature, No. 117, Summer, 1988.

Fanon, Frantz. 1967-85 "On National Culture" in The Wretched of the Earth. New York: Penguin. P. 193.

Hanur, Krishnamurthy. 1993. Myasabedara Samskriti, Karnataka Sahitya Academy, Bangalore.

Hermans, Theo. 1985. "Why Waste our time on rewrites? The trouble 
with Interpretation and the role of rewriting in an alternative paradigm" in Theo Hermans. Ed. The Manipulation of Literature Studies in Literary Translation. Croom Helen: London, Print.

Levis-Strauss, Claude. 1976. Structural Anthropology Vol 2. Trans. Monique Layton. New York: Penguin, Print.

Manguel, Alberto. 1997. A History of Reading, London, Flamingo, Print.

McGuire, Susan Bassnett. 1980. Translation Studies. London: Routledge, Print. 